\title{
Relation between Communicative Tolerance and Intercultural Adaptation in International Students
}

\author{
Irina A. Novikova \\ Peoples' Friendship University of Russia \\ Novikova_ia@pfur.ru \\ Alexey L. Novikov \\ Peoples' Friendship University of Russia \\ Novikov_al@pfur.ru
}

\section{Doi:10.5901/mjss.2015.v6n2s2p109}

\begin{abstract}
The paper presents the results of a study of the connection between the parameters of the communicative tolerance and the intercultural adaptation in the international students from a multinational university (Peoples' Friendship University of Russia). A total of 337 respondents took part in the research, including 182 young men and 155 young women from five parts of the world: Latin America, Asia (China), Arab countries, Africa, the countries of the Central Asian region. The level of the communicative tolerance was measured with the technique "General communicative tolerance" by V.V.Boyko. The Questionnaire of the adaptation of the person to the new socio-cultural environment (APSCE) by L.V.Yankovsky, in T.G.Stefanenko and M.S.Panov's modified version was used to define the features of the intercultural adaptation of the international students. The Kruskal-Wallis non-parametrical criteria, the Analysis of Variance (MANOVA), and the correlation analysis (Spearman Rank Correlations) were used for the statistical analysis. The study revealed that the rates of the communicative tolerance, as a whole, are positively related to the efficiency of the intercultural adaptation of the international students in Russia (especially for the students from Africa, Arab countries and Latin America).
\end{abstract}

Keywords: Intercultural Adaptation, Tolerance, Communicative Tolerance, International Students, Multinational University.

\section{Introduction}

In the twenty-first century the academic mobility of students is growing all over the world including Russian Federation. Russian education is becoming more and more attractive to international students, and every year the quantity of students, coming to study in the Russian universities increases (Chebotareva, 2011). But the majority of the foreign students faced with difficulties in adapting to a new culture that can influence on the training effectiveness. So the study of the intercultural adaptation problems in the international students is very relevant. The study of this problem has a special importance for a multinational university such as the Peoples' Friendship University of Russia (PFUR).

In February 2015, the PFUR celebrates 55 years since its foundation. Today the PFUR is one of the leading state higher educational institutions in Russian Federation. It is the only university in the world every year uniting more than 29 thousand graduate and postgraduate students from 145-150 countries. They represent more than 450 nations and nationalities of the world (About PFUR, 2014). The mission of PFUR is to unite the people of different nationalities, races and religious beliefs with the help of knowledge, and also to educate the youth capable to work in any country of the world successfully and to show their creative abilities in the conditions of the interrelation of civilizations and the variety of the modern society (PFUR Mission, 2014).

The team at the PFUR Center for personality studies has conducted a number of basic and applied studies on ethnic characteristics and personality traits, cross-cultural communication and adaptation (Chebotareva, 2011, 2014; Chebotareva, Novikova, 2013; Kovalenko et al., 2009; Novikova, Novikov, 2014). These studies are mainly based on a System and Functional approach to analysis of personality and behavior, developed by Alexander Krupnov (Krupnov, Novikova, Kozhukhova, 2013). This approach provides the opportunity to explore not only separate aspects of some phenomenon, but whole systems, taking into account the hierarchy and interaction of their components. A number of psychodiagnostic and correctional programs have been developed in this way. The scientists of PFUR have also carried out a series of studies on problems of intercultural communication and adaptation of students from Asia, Africa, South 
America, the Middle East, and the former Soviet countries. In this research they have emphasized the role of such characteristics as gender, Russian language acquisition, ethnic identity, values, tolerance, emotional intelligence, hardiness, etc (Chebotareva, 2011; Kovalenko et al., 2009; Maslova, 2011; Novikov, Novikova, 2013; Novikov, Novikova, Shkvarilo, 2013; Novikova, 2011).

We suppose that one of the most important factors of intercultural adaptation is tolerance. The tolerance is considered from different points of view in the modern Western psychology: as the value of personality, as the attitude, and as a personality trait (Craig, Richeson, 2008; Davies, Steele, Markus, 2008; Foulkes, Foulkes, 1965; Ibadova, 2011). Russian psychologists are studying different kinds of tolerance, for example, ethnic, social, communicative, and others (Soldatova, Shaigerova, 2008).

Since 2007 we have been studying tolerance in the Russian and international PFUR students in the context of the intercultural communication and adaptation (Novikova, 2011; Novikova, Novikov, 2013). For example, we identified four types of tolerance among international students:

- "Real tolerant" students have higher indicators for all three types of tolerance and the most harmonious character of cross-cultural adaptation;

- "Ethnic tolerant" students have high levels of the ethnic and personality tolerance, but low social tolerance, and they do not have many problems with adapting to a new culture;

- "Tolerant in social communications" students have a high level of social tolerance, but are moderate in personality tolerance and low in ethnic tolerance, and they are not very satisfied with their adaptation in a foreign country, and they do not seek to be included in the new environment, but they do not have strong nostalgia, anxiety, or helplessness;

- "Intolerant" students have the lowest indicators for all three types of tolerance, and ambivalent indicators of intercultural adaptation: they are ready to interact with the new environment, but have strong feelings of anxiety, depression, emptiness, isolation, and helplessness (Novikova, Novikov, 2013).

In this paper we present a study of the communicative tolerance among the PFUR international students in correlation with the features of their intercultural adaptation.

Communicative tolerance is a characteristic of the personality attitude to the other people. It shows the degree of the tolerability to an unpleasant or inappropriate psychological states, qualities and actions of the interaction partners. According to V. Boyko overall communicative tolerance is due to life experiences, personality traits, the moral principles of human (Boyko, 1996).

The aims of our study is:

1) to compare the level of the communicative tolerance in PFUR international students from different regions of the world;

2) to reveal connection between the parameters of the communicative tolerance and intercultural adaptation in the PFUR international students from different regions of the world.

The basic hypothesis is that the communicative tolerance level positively related with the intercultural adaptation efficiency of the PFUR international students from different regions of the world.

\section{Method}

In our research the communicative tolerance level was measured by the technique "General communicative tolerance" by V.V.Boyko, which includes 9 scales:

1) Misunderstanding of the another person individuality;

2) Using himself as a standard for the assessing other persons' behavior and mentality;

3) Being conservative when evaluating other persons;

4) Being unable to hide unpleasant feelings when confronting non-sociable partners;

5) The intention to correct some of the partners' traits;

6) The intention to fit partner for himself, make it "convenient";

7) Being unable to forgive other persons' mistakes, their awkwardness or accidental troubles they cause;

8) Being intolerant to the physical or mental discomfort caused by other persons;

9) Being unable to accommodate to the other persons' nature, habits and desires.

High rates on each scale indicate a high intolerance in communication. The sum of all scales is The General index of the Communicative tolerance (intolerance).

The Questionnaire of adaptation of the person to the new socio-cultural environment (APSCE) by L.V.Yankovsky, in T.G.Stefanenko, M.S.Panov's modified version was used to define the features of the intercultural adaptation of the 
international students. This Questionnaire includes six scales:

- the Contentment scale reflects the degree of personal satisfaction, feelings of social and physical security, a sense of belonging to a new society and the level of activity in the new environment;

- the Interactivity scale reflects the degree of disposition to the expansion of social relations in the new society, focusing on the cooperation with the others and following the social norms;

- the Conformity scale reflects the degree of the orientation on social approval, depending on the group, the need for affection and emotional relationships with people;

- the Depression scale reflects the level of helplessness in the face of life difficulties, feelings of hopelessness, doubt, anxiety, depression, emptiness, isolation;

- the Nostalgia scale reflects the degree of internal disorder caused by the separateness of traditional values and norms, and a sense of dreamy, anguish, melancholy;

- the Alienation scale reflects the level of rejection of the new society, claims of inconsistency and real opportunities, feelings of loneliness, impatience, helplessness.

The first three scales (contentment, interactivity, conformity) correspond to rather "positive" intercultural adaptation indicators, and the last three scales (depression, nostalgia, alienation) indicate certain adaptation problems. But research showed that nostalgia is highly manifested in most international students and its level is positively related to the positive adaptation parameters (Chebotareva, 2011; Maslova, 2011; Novikova, 2011 etc).

The Kruskal-Wallis non-parametrical criteria and Analysis of Variance (MANOVA) was used to define differences between the indicators of communicative tolerance in the subgroups of students from different regions. The relations between the parameters of the communicative tolerance and intercultural adaptation were revealed with the help of the Spearmen Rank correlations.

A total of 337 respondents took part in the research, including 182 young men and 155 young women from five parts of the world: Latin America, Asia (China), Arab countries, Africa, the countries of the Central Asian region (former Soviet Republics). All the respondents were the first, second and third year students of the various PFUR departments.

\section{Results}

The results of technique "General communicative tolerance" are presented in the Table 1.

It was founded eight significant differences between the studied groups of students on the communicative intolerance parameters, including The General index.

Significant differences between students from different regions were discovered on the first scale "Misunderstanding of the another person individuality". Chinese students got relatively higher results on that scale, which means that they will show more intolerant attitude to individual manifestations of their partners (slowness or restlessness, originality or irregularity, etc.).

Significant differences between students from different regions were also discovered on the second scale "Using himself as a standard for the assessing other persons' behavior and mentality". Students from Central Asian Region got the lowest results, which means they will less likely react negatively in case if their partner is different from them (different intellectual level, being more or less initiative in communication, etc.)

Great differences between students from different regions were discovered on the fourth scale "Being unable to hide himself unpleasant feelings when confronting non-sociable partners". Chinese and Central Asian students got the lowest results, which means that they will likely hide their negative emotions; Latin American and Arabian students got higher results (they do not find hiding their true negative feelings toward their partners necessary).

Significant differences between students from different regions were also discovered on the fifth scale "The intention to correct some of the partners' traits". Central Asian students got the lowest results; they do not tend to make offending comments on someone's behavior in order to make said behavior better.

Significant differences between students from different regions were also discovered on the seventh scale "Being unable to forgive other persons' mistakes, their awkwardness or accidental troubles they cause". Central Asian students got the lowest results, they do not tend to feel offended and maintain that feeling for a long time, if the original offence has been accidental.

Significant differences between students from different regions were also discovered on the eighth and ninth scales "Being intolerant to the physical or mental discomfort caused by other persons" and "Being unable to accommodate to the other persons' nature, habits and desires" respectively. The differences are similar: Central Asian students got the lowest results (the lowest comparing to the other scales) which significantly differ, pairwise, from the results of the students from other regions. That means that Central Asian students are more attentive to their partners and adaptation to "difficult" 
partners is easier for them.

Significant differences between students from different regions were also discovered on The General index of communicative tolerance. The differences are similar to the aforementioned: Central Asian students have the lowest index $(42,9)$ which differs, pairwise, from the total indexes of the other students $(52,3-55,6)$.

Such a way, students from Central Asia, in most cases are characterized by higher rates of the communicative tolerance toward partner in the communication.

Table 2 represents the result of the correlation analysis between the Communicative Tolerance and Intercultural Adaptation indicators.

19 significant correlations between indicators of the communicative tolerance and intercultural adaptation are received in a subgroup of the African students. The majority of them are between tolerance (intolerance) indicators and depression and alienation. The general sense of the given correlations consists that the African students who are less tolerant in the communications (more categorical, intolerant, not accepting the individuality of the partner, not able to forgive others, etc.) have more problems in the course of the adaptation, connected with negative emotional experiences, sensations of disconnection, forlornness, etc.

13 significant correlations between scales of used techniques are revealed in a subgroup of the Arabian students. Substantially given communications mean that, as well as in the previous group, the Arabian students who are less tolerant in the course of communications, have more problems in the course of the adaptation, connected with emotional experiences, sensations of disconnection, inability to come into contact to associates, etc. In whole, correlations between communicative problems (first of all, connected with "an extension from above" in the course of dialogue) and the difficulties in intercultural adaptation proves to be true in the given subgroup.

22 significant correlations between communicative tolerance and intercultural adaptation indicators are established in a subgroup of the Chinese students. Character of correlations between the first and third scales of the Communicative intolerance and the parameters of Intercultural adaptation corresponds to the trends obtained in other subgroups of students. It is possible to say that the Chinese students who are more categorical in estimations of others have more problems in the course of adaptation. However, on the fourth, sixth, ninth scale negative correlations are received both with interactivity and conformity, and with depression and alienation. The General indicator of the communicative tolerance negatively correlates as with contentment, interactivity, conformity and with depression.

14 significant correlations between scales of the given techniques are revealed in a subgroup of the Latin American students. The substantial sense of the given correlations consists that (as well as in a subgroup of the African and Arabian students) the Latin American students who are less tolerant in the course of communications, have more problems in the course of adaptation.

It is revealed only 1 significant correlation between scales of used techniques in a subgroup of students from Central Asia. It testifies to relative independence of indicators of communicative tolerance and adaptation in group of students of Central Asia.

\section{Discussion}

Most of the examined PFUR international students have average indicators of the communicative tolerance. Students from Central Asia, in most cases are characterized by higher rates of tolerance toward partner in the communication. This data are correspond to results obtained by another method (Novikova, 2011). Chinese students have more intolerant attitude to individual manifestations of their partners (slowness or restlessness, originality or irregularity, etc.), but they (like Central Asia students) will likely hide their negative emotions. Latin American and Arabian students are much more often do not hiding their true negative feelings toward their partners necessary.

The comparative analysis of correlations between indicators of the Communicative Tolerance and Intercultural Adaptation has shown that there is no communication which would repeat in all five subgroups of students, but positive relations between the intolerant communicative attitudes and depression and alienation are the most stable. It is possible to say that in most cases the international students with more tolerant communicative attitudes (aspiration to understand and accept individuality of another, tolerance to features of the partner, absence of desire it to re-educate, adjust to himself, etc.) have less problems in the course of intercultural adaptation.

There is more strongly pronounced specificity of communications in general and intercultural communications, in particular, in the Chinese student subgroup. That is the Chinese students who are less intolerant in the course of communications, as a whole, better adapt for a new environment, but more strongly endure depression, disconnection, more strongly miss the motherland. Thus, it is possible to tell that the communicative tolerance in Chinese students group, certainly, is connected with features of their intercultural adaptation. However, as process of communications in 
the Chinese culture has certain features, character of the given correlations not always corresponds to the tendencies revealed in other subgroups of international students. It is possible to assume also that the part of the Chinese students prefers to adapt together with own ethnic group, and some of them choose "individual style of adaptation". Hence, in the course of working out of various communicative trainings for the Chinese students it is necessary to develop for them additional exercises, taking into account ethnopsychological specificity.

And it is necessary to disclose the factors more closely connected to intercultural adaptation parameters than communicative tolerance in the Central Asia student subgroup.

\section{Conclusions}

Summing up the results of the study, it can be concluded that:

- Most of the examined PFUR international students have average indicators of the communicative tolerance; students from Central Asia in most cases are characterized by higher rates of tolerance toward partner in the communication;

- The level of communicative tolerance, as a whole, is one of the positive factors of intercultural adaptation (especially for the students from Africa, the Arabian countries and Latin America);

- It is necessary to develop the programs of individual and group psychological and pedagogical work with the PFUR international students from the different regions, aimed at developing in them the tolerant attitudes to different cultures in general, to the Russian culture, in particular, towards accepting the variety of the world around, forming tolerant communicative attitudes on the basis of the received data.

\section{References}

About PFUR (2014). Retrieved from http://www.rudn.ru/en/?pagec=3

Boyko, V.V. (1996). The energy of emotions in communication: a look at yourself and others. Moscow: Filin (in Russian).

Chebotareva, E. Ju. (2011). Intercultural adaptation to Russia of students from Asia, Africa, Latin America and the Middle East. Bulletin of Peoples' Friendship University of Russia, Series "Psychology and Pedagogics", 3, 6-11.

Chebotareva, E. (2014). Multi-Dimensional and Functional Approach to the intercultural adaptation study. Journal of Educational and Social Research, Vol.4 (2), 170-174.

Chebotareva, E. (2014). Psychological factors of ethnic extremism in Muslim youth. Mediterranean Journal of Social Sciences, Vol. 5 (19), 676-684.

Chebotareva. E.Yu., Novikova I.A. (2013). Russian Psychology: Ethnic and Cross-Cultural. In Kenneth D. Keith (Ed.), The Encyclopedia of Cross-Cultural Psychology. Hoboken, New Jersey: Wiley-Blackwell (pp. 1111-1115).

Craig M., Richeson J. (2008). More Diverse Yet Less Tolerant? How the Increasingly Diverse Racial Landscape Affects White Americans' Racial Attitudes. Personality and Social Psychology Bulletin, Vol. 40 (6), 750-761.

Davies. P., Steele. C., Markus. H. (2008). A Nation Challenged: The Impact of Foreign Threat on America's Tolerance or Diversity. Journal of Personality and Social Psychology, Vol. 95 (2), 308-318.

Foulkes. D., Foulkes. S. (1965) Self-concept, Dogmatism and Tolerance of Traits Inconsistency. Journal of Personality and Social Psychology, Vol. 2 (1), 104-110.

Ibadova, T.I. (2011)The Problem of Tolerance in Modern Foreign Psychology. Bulletin of Peoples' Friendship University of Russia. Series: Psychology and Pedagogics, 3, 68-74.

Krupnov, A.I., Novikova, I.A., Kozhukhova, Y.V. (2013). System-Functional Model of Personality Traits. Academic Journal of Interdisciplinary Studies, 2 (3), 407-413.

Kovalenko, A.G., Chebotareva, E.Yu., Mikheeva, N.F., Larina, T.V., Novikova, I.A., Ebzeeva Yu.N., Maslova, O.V, Volk, M.I, Ibadova, T.I. (2009). Intercultural Communication: Linguistic and Psychological Aspects: Collective monograph. Moscow, Russia: Peoples' Friendship University of Russia (in Russian).

Maslova, O.V. (2011)Basic Beliefs of Personality as Resource of Adaptation to New Culture. Bulletin of Peoples' Friendship University of Russia. Series: Psychology and Pedagogics, 3, 12-18 (in Russian).

Novikov, A., Novikova, I., Shkvarilo, K. (2013). Psychological and linguistic specifics of the foreign language acquisition by multinational university students. In Language and Super-diversity: Explorations and interrogations: Abstracts. Jyvaskyla, Finland (pp.179180).

Novikov. A.L., Novikova. I.A. Social Representations of Russian Cuisine in Multinational University Students // Mediterranean Journal of Social Science. - 2013. - Vol. 4. - No 11. - P. 413-417.

Novikova, I. (2011) Tolerance as a factor of intercultural adaptation of foreign students. In E. Khakimov (Ed.) Education and Interethnic relations: Book of articles. Izhevsk: Udmurt State University (pp.149-158).

Novikova, I.A., Novikov, A.L. (2013). Tolerance Types and Features of Intercultural Adaptation in International Students. Journal of Educational and Social Research, Vol.3 (7), 625-630.

PFUR Mission (2014) Retrieved from http://www.rudn.ru/en/?pagec=636 
Soldatova, G.U., Shaigerova. L.A. (Eds) (2008) Psychodiagnostics of the personality tolerance. Moscow, Russia: Smysl (in Russian).

\section{Footnotes}

The publication of this paper is devoted to the 55th anniversary of People's Friendship University of Russia.

\section{Tables}

Table 1: Statistical evaluation of differences on indicators of the technique "General communicative tolerance" between the international students from the different regions

\begin{tabular}{|c|c|c|c|c|c|c|c|c|c|}
\hline Regions & Count & Mean & Median & St.dev. & Min. & Max. & Range & Kruskal-Wallis Test & Analysis of Variance $D f=4$ \\
\hline 1 & 2 & 3 & 4 & 5 & 6 & 7 & 8 & 9 & 10 \\
\hline \multicolumn{10}{|c|}{ 1. Misunderstanding of the another person individuality } \\
\hline Africa & 58 & 5,39 & 5,0 & 3,43 & 0,0 & 15,0 & 15,0 & \multirow{3}{*}{$H=20,06$} & \multirow[b]{2}{*}{$F=4,37$} \\
\hline Arab.countries & 77 & 5,89 & 6,0 & 3,05 & 0,0 & 12,0 & 12,0 & & \\
\hline China & 80 & 7,08 & 7,5 & 2,77 & 0,0 & 12,0 & 12,0 & & \multirow{4}{*}{$\begin{array}{c}P \text {-Value }= \\
0,0019\end{array}$} \\
\hline Latin America & 69 & 5,42 & 5,0 & 3,35 & 0,0 & 15,0 & 15,0 & \multirow{3}{*}{$\begin{array}{c}P \text {-Value }= \\
0,00048\end{array}$} & \\
\hline Central Asia & 53 & 5,05 & 5,0 & 3,06 & 0,0 & 10,0 & 10,0 & & \\
\hline Totals & 337 & 5,86 & 6,0 & 3,19 & 0,0 & 15,0 & 15,0 & & \\
\hline \multicolumn{10}{|c|}{ 2. Using himself as a standard when assessing other persons' behavior and mentality } \\
\hline Africa & 58 & 5,93 & 6,0 & 3,36 & 0,0 & 15,0 & 15,0 & \multirow{6}{*}{$H=11,611$} & \multirow{3}{*}{$F=3,04$} \\
\hline Arab.countries & 77 & 5,94 & 7,0 & 3,15 & 0,0 & 13,0 & 13,0 & & \\
\hline China & 80 & 6,18 & 6,0 & 2,39 & 0,0 & 11,0 & 11,0 & & \\
\hline Latin America & 69 & 6,07 & 6,0 & 3,44 & 0,0 & 15,0 & 15,0 & & \multirow{3}{*}{$\begin{array}{c}P \text {-Value }= \\
0,0175\end{array}$} \\
\hline Central Asia & 53 & 4,50 & 4,0 & 2,95 & 0,0 & 11,0 & 11,0 & & \\
\hline Totals & 337 & 5,80 & 6,0 & 3,09 & 0,0 & 15,0 & 15,0 & & \\
\hline \multicolumn{10}{|c|}{ 3. Being conservative when evaluating other persons } \\
\hline Africa & 58 & 6,22 & 6,0 & 3,45 & 0,0 & 15,0 & 15,0 & \multirow{6}{*}{$H=6,924$} & \multirow{3}{*}{$F=1,48$} \\
\hline Arab.countries & 77 & 6,49 & 7,0 & 3,22 & 0,0 & 15,0 & 15,0 & & \\
\hline China & 80 & 6,90 & 7,0 & 2,45 & 0,0 & 10,0 & 10,0 & & \\
\hline Latin America & 69 & 6,72 & 7,0 & 3,06 & 0,0 & 15,0 & 15,0 & & \multirow{3}{*}{$\begin{array}{c}P \text {-Value }= \\
0,2082\end{array}$} \\
\hline Central Asia & 53 & 5,64 & 6,0 & 3,29 & 0,0 & 13,0 & 13,0 & & \\
\hline Totals & 337 & 6,45 & 7,0 & 3,08 & 0,0 & 15,0 & 15,0 & & \\
\hline \multicolumn{10}{|c|}{ 4. Being unable to hide one's unpleasant feelings when confronting non-sociable partners } \\
\hline Africa & 58 & 6,39 & 7,0 & 3,67 & 0,0 & 15,0 & 15,0 & \multirow{6}{*}{$\begin{array}{c}H=20,903 \\
P \text {-Value }= \\
0,00033\end{array}$} & \multirow[b]{2}{*}{$F=3,86$} \\
\hline Arab.countries & 77 & 7,05 & 7,0 & 4,88 & 0,0 & 14,0 & 14,0 & & \\
\hline China & 80 & 5,11 & 5,0 & 2,86 & 0,0 & 11,0 & 11,0 & & \multirow{4}{*}{$\begin{array}{c}P \text {-Value }= \\
0,0045\end{array}$} \\
\hline Latin America & 69 & 6,84 & 7,0 & 3,25 & 0,0 & 13,0 & 13,0 & & \\
\hline Central Asia & 53 & 5,13 & 5,0 & 2,82 & 0,0 & 12,0 & 12,0 & & \\
\hline Totals & 337 & 6,13 & 6,0 & 3,70 & 0,0 & 15,0 & 14,0 & & \\
\hline \multicolumn{10}{|c|}{ 5. The intention to correct some of the partners' traits } \\
\hline Africa & 58 & 5,94 & 7,0 & 3,50 & 0,0 & 14,0 & 14,0 & \multirow{6}{*}{$H=9,69939$} & \multirow{3}{*}{$F=2,53$} \\
\hline Arab.countries & 77 & 5,85 & 6,0 & 3,03 & 0,0 & 12,0 & 12,0 & & \\
\hline China & 80 & 6,40 & 6,0 & 2,54 & 0,0 & 12,0 & 12,0 & & \\
\hline Latin America & 69 & 6,47 & 7,0 & 3,57 & 0,0 & 13,0 & 13,0 & & \multirow{3}{*}{$\begin{array}{c}\text { P-Value }= \\
0,0406\end{array}$} \\
\hline Central Asia & 53 & 4,83 & 5,0 & 3,42 & 0,0 & 15,0 & 15,0 & & \\
\hline Totals & 337 & 5,96 & 6,0 & 3,22 & 0,0 & 15,0 & 15,0 & & \\
\hline \multicolumn{10}{|c|}{ 6. The intention to fit partner for themselves, make it "convenient" } \\
\hline Africa & 58 & 5,98 & 7,0 & 3,56 & 0,0 & 15,0 & 15,0 & & \\
\hline Arab.countries & 77 & 6,33 & 7,0 & 3,05 & 0,0 & 13,0 & 13,0 & 953 & $F=1,31$ \\
\hline China & 80 & 5,88 & 6,0 & 2,40 & 0,0 & 11,0 & 11,0 & & \\
\hline Latin America & 69 & 5,81 & 6,0 & 3,37 & 0,0 & 14,0 & 14,0 & $P$-value = & $P$-Value $=$ \\
\hline Central Asia & 53 & 5,03 & 5,0 & 2,89 & 0,0 & 12,0 & 12,0 & & 0,2672 \\
\hline Totals & 337 & 5,85 & 6,0 & 3,06 & 0,0 & 15,0 & 15,0 & & \\
\hline 1 & 2 & 3 & 4 & 5 & 6 & 7 & 8 & 9 & 10 \\
\hline
\end{tabular}




\begin{tabular}{|c|c|c|c|c|c|c|c|c|c|}
\hline Africa & 58 & 5,37 & 5,0 & 3,02 & 0,0 & 12,0 & 12,0 & \multirow{6}{*}{$\begin{array}{c}H=14,689 \\
P \text {-Value }= \\
0,00539\end{array}$} & \multirow{6}{*}{$\begin{array}{c}F=2,67 \\
P \text {-Value }= \\
0,0321\end{array}$} \\
\hline Arab.countries & 77 & 6,10 & 6,0 & 2,99 & 0,0 & 14,0 & 14,0 & & \\
\hline China & 80 & 6,17 & 7,0 & 2,48 & 0,0 & 11,0 & 11,0 & & \\
\hline Latin America & 69 & 6,24 & 7,0 & 3,10 & 0,0 & 12,0 & 12,0 & & \\
\hline Central Asia & 53 & 4,83 & 5,0 & 2,95 & 0,0 & 14,0 & 14,0 & & \\
\hline Totals & 337 & 5,82 & 6,0 & 2,93 & 0,0 & 14,0 & 14,0 & & \\
\hline \multicolumn{10}{|c|}{ 8. Being intolerant to physical or mental discomfort caused by other persons } \\
\hline Africa & 58 & 5,81 & 6,0 & 3,61 & 0,0 & 15,0 & 15,0 & \multirow{6}{*}{$\begin{array}{c}H=20,649 \\
P \text {-Value }= \\
0,00037\end{array}$} & \multirow{6}{*}{$\begin{array}{c}F=4,79 \\
P \text {-Value }= \\
0,0009\end{array}$} \\
\hline Arab.countries & 77 & 5,49 & 6,0 & 3,29 & 0,0 & 11,0 & 11,0 & & \\
\hline China & 80 & 5,96 & 6,5 & 2,78 & 0,0 & 11,0 & 11,0 & & \\
\hline Latin America & 69 & 6,08 & 7,0 & 3,64 & 0,0 & 15,0 & 15,0 & & \\
\hline Central Asia & 53 & 3,83 & 4,0 & 2,50 & 0,0 & 12,0 & 12,0 & & \\
\hline Totals & 337 & 5,51 & 6,0 & 3,27 & 0,0 & 15,0 & 15,0 & & \\
\hline \multicolumn{10}{|c|}{ 9. Being unable to accommodate to the other persons' nature, habits and desires } \\
\hline Africa & 58 & 5,24 & 5,5 & 3,17 & 0,0 & 12,0 & 12,0 & \multirow{6}{*}{$\begin{array}{c}H=11,007 \\
P-\text { Value }= \\
0,02648\end{array}$} & \multirow{6}{*}{$\begin{array}{c}F=2,86 \\
P-\text { Value }= \\
0,0235\end{array}$} \\
\hline Arab.countries & 77 & 5,50 & 5,0 & 3,22 & 0,0 & 13,0 & 13,0 & & \\
\hline China & 80 & 5,48 & 6,0 & 3,08 & 0,0 & 11,0 & 11,0 & & \\
\hline Latin America & 69 & 5,92 & 6,0 & 3,78 & 0,0 & 13,0 & 13,0 & & \\
\hline Central Asia & 53 & 4,03 & 4,0 & 2,59 & 0,0 & 9,0 & 9,0 & & \\
\hline Totals & 337 & 5,31 & 5,0 & 3,25 & 0,0 & 13,0 & 13,0 & & \\
\hline \multicolumn{10}{|c|}{ General index of communicative tolerance (intolerance) } \\
\hline Africa & 58 & 52,31 & 58,0 & 24,93 & 0,0 & 105,0 & 105,0 & \multirow{6}{*}{$\begin{array}{c}H=18,162 \\
P \text {-Value }= \\
0,00114\end{array}$} & \multirow{6}{*}{$\begin{array}{c}F=3,63 \\
P \text {-Value }= \\
0,0065\end{array}$} \\
\hline Arab.countries & 77 & 54,68 & 59,0 & 22,33 & 0,0 & 101,0 & 101,0 & & \\
\hline China & 80 & 55,20 & 58,5 & 17,01 & 0,0 & 79,0 & 79,0 & & \\
\hline Latin America & 69 & 55,60 & 61,0 & 22,58 & 0,0 & 102,0 & 102,0 & & \\
\hline Central Asia & 53 & 42,90 & 43,0 & 20,02 & 0,0 & 81,0 & 81,0 & & \\
\hline Totals & 337 & 52,73 & 58,0 & 21,69 & 0,0 & 105,0 & 105,0 & & \\
\hline
\end{tabular}

Table 2: Correlation coefficients between the indicators of the Communicative Tolerance and Intercultural Adaptation for the international students from the different regions

\begin{tabular}{|c|c|c|c|c|c|c|}
\hline \multirow{2}{*}{ Scale Com. Tolerance } & \multicolumn{6}{|c|}{ Intercultural adaptation } \\
\hline & Contentment & Interactivity & Conformity & Depression & Nostalgia & Alienation \\
\hline 1 & 2 & 3 & 4 & 5 & 6 & 7 \\
\hline \multicolumn{7}{|c|}{ Students from Africa $(n=58)$} \\
\hline 1 & $-0,32^{\star \star}$ & $-0,26^{*}$ & $-0,23$ & $0,28^{*}$ & $-0,07$ & $0,29 *$ \\
\hline 2 & $-0,16$ & $-0,24$ & $-0,32^{\star *}$ & $0,33^{\star \star}$ & $-0,28^{*}$ & $0,23^{*}$ \\
\hline 3 & $-0,17$ & $-0,15$ & $-0,30^{*}$ & $0,31^{*}$ & $-0,24$ & $0,25^{*}$ \\
\hline 4 & $-0,08$ & $-0,13$ & $-0,20$ & $0,38^{\star \star}$ & $-0,12$ & $0,27^{*}$ \\
\hline 5 & 0,10 & 0,06 & $-0,11$ & 0,20 & $-0,10$ & 0,06 \\
\hline 6 & $-0,00$ & $-0,07$ & $-0,11$ & $0,30^{*}$ & $-0,16$ & 0,17 \\
\hline 7 & $-0,00$ & 0,03 & $-0,02$ & 0,20 & 0,05 & 0,13 \\
\hline 8 & $-0,27^{\star}$ & $-0,11$ & $-0,18$ & $0,33^{\star \star}$ & $-0,25^{\star}$ & 0,08 \\
\hline 9 & 0,11 & $-0,05$ & $-0,11$ & 0,04 & $-0,07$ & 0,07 \\
\hline Gen.Index & $-0,08$ & $-0,14$ & $-0,25^{\star}$ & $0,41^{\star \star \star}$ & $-0,24$ & 0,25 \\
\hline 1 & 2 & 3 & 4 & 5 & 6 & 7 \\
\hline \multicolumn{7}{|c|}{ Students from the Arabian countries $(n=77)$} \\
\hline 1 & 0,06 & $-0,07$ & $-0,07$ & $0,28 * *$ & 0,13 & $0,37^{\star \star \star}$ \\
\hline 2 & 0,08 & $-0,03$ & $-0,00$ & $-0,01$ & 0,07 & 0,03 \\
\hline 3 & 0,12 & 0,04 & 0,00 & $0,28 * \star$ & $0,24^{*}$ & 0,19 \\
\hline 4 & 0,01 & 0,01 & $-0,03$ & $0,26^{*}$ & 0,10 & $0,33^{\star \star}$ \\
\hline 5 & $-0,00$ & $-0,03$ & 0,03 & 0,13 & 0,04 & 0,13 \\
\hline 6 & 0,06 & 0,10 & 0,04 & $0,31^{\star *}$ & 0,08 & 0,18 \\
\hline 7 & $-0,00$ & 0,02 & 0,02 & 0,15 & 0,02 & $0,32^{\star \star}$ \\
\hline 8 & $-0,03$ & $-0,07$ & $-0,12$ & $0,32^{\star \star}$ & 0,10 & 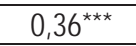 \\
\hline 9 & 0,00 & 0,00 & 0,07 & $0,37^{\star \star \star}$ & 0,16 & 0,12 \\
\hline Gen.Index & 0,08 & $-0,00$ & $-0,01$ & $0,23^{*}$ & 0,11 & $0,25^{\star}$ \\
\hline
\end{tabular}




\begin{tabular}{|c|c|c|c|c|c|c|}
\hline \multicolumn{7}{|c|}{ Students from Latin America ( $n=69$ ) } \\
\hline 1 & 0,07 & 0,01 & $0,24^{*}$ & 0,19 & $-0,04$ & 0,06 \\
\hline 2 & 0,03 & $-0,00$ & 0,05 & $0,27^{*}$ & $-0,09$ & 0,09 \\
\hline 3 & $-0,08$ & $-0,00$ & 0,18 & 0,20 & 0,11 & 0,16 \\
\hline 4 & 0,05 & 0,09 & 0,11 & 0,10 & $-0,03$ & 0,07 \\
\hline 5 & 0,05 & 0,14 & $-0,00$ & $0,47^{\star \star \star}$ & $-0,11$ & $0,24^{*}$ \\
\hline 6 & $-0,05$ & $-0,01$ & $-0,08$ & $0,38^{* *}$ & $-0,10$ & $0,27^{*}$ \\
\hline 7 & 0,02 & 0,22 & $-0,11$ & $0,27^{*}$ & $-0,05$ & 0,31 ** \\
\hline 8 & $-0,03$ & 0,21 & $-0,20$ & $0,27^{*}$ & $-0,18$ & $0,36^{\star \star}$ \\
\hline 9 & 0,10 & 0,11 & $-0,02$ & $0,27^{*}$ & $-0,11$ & $0,25^{*}$ \\
\hline Gen.Index & $-0,02$ & 0,05 & $-0,05$ & $0,35^{\star \star}$ & $-0,16$ & $0,29^{*}$ \\
\hline 1 & 2 & 3 & 4 & 5 & 6 & 7 \\
\hline \multicolumn{7}{|c|}{ Students from Asia (China) $(n=80)$} \\
\hline 1 & $-0,35^{\star \star \star}$ & 0,03 & $-0,14$ & $0,26^{*}$ & $-0,05$ & $0,43^{\star \star \star}$ \\
\hline 2 & $-0,03$ & $-0,05$ & 0,05 & $-0,20$ & $-0,11$ & $-0,21$ \\
\hline 3 & 0,019 & 0,21 & 0,13 & $0,26^{*}$ & 0,01 & 0,29 ** \\
\hline 4 & $-0,09$ & $-0,30$ ** & $-0,23^{*}$ & $-0,42^{\star \star \star}$ & 0,00 & $-0,33^{* *}$ \\
\hline 5 & $-0,24^{*}$ & $-0,13$ & $-0,09$ & $-0,20$ & 0,14 & $-0,10$ \\
\hline 6 & $-0,11$ & $-0,34^{\star *}$ & $-0,25^{\star}$ & $-0,45^{\star \star \star}$ & $-0,08$ & $-0,44^{\star \star \star}$ \\
\hline 7 & $-0,09$ & 0,01 & 0,09 & $-0,00$ & $-0,00$ & 0,07 \\
\hline 8 & $-0,23^{*}$ & $-0,16$ & $-0,12$ & 0,02 & 0,07 & 0,14 \\
\hline 9 & $-0,18$ & $-0,42^{\star \star \star}$ & $-0,29 \star \star$ & $-0,38^{\star \star \star}$ & 0,03 & $-0,21$ \\
\hline Gen.Index & $-0,31^{* *}$ & $-0,32^{\star *}$ & $-0,26^{*}$ & $-0,27^{\star}$ & 0,04 & $-0,06$ \\
\hline \multicolumn{7}{|c|}{ Students from the Central Asian region $(n=53)$} \\
\hline 1 & 0,03 & 0,09 & 0,17 & 0,17 & $0,28^{*}$ & 0,10 \\
\hline 2 & 0,06 & 0,05 & 0,05 & 0,10 & 0,18 & 0,06 \\
\hline 3 & 0,14 & 0,04 & 0,12 & 0,07 & 0,11 & 0,04 \\
\hline 4 & 0,08 & 0,09 & 0,05 & $-0,02$ & 0,03 & 0,01 \\
\hline 5 & 0,07 & 0,01 & 0,05 & 0,14 & 0,16 & $-0,10$ \\
\hline 6 & 0,07 & $-0,05$ & $-0,00$ & 0,20 & 0,09 & 0,14 \\
\hline 7 & $-0,13$ & $-0,14$ & $-0,03$ & 0,14 & 0,25 & 0,01 \\
\hline 8 & 0,11 & 0,05 & $-0,05$ & 0,08 & $-0,21$ & 0,09 \\
\hline 9 & 0,06 & $-0,14$ & 0,01 & 0,14 & 0,09 & 0,09 \\
\hline Gen.Index & 0,05 & $-0,01$ & 0,06 & 0,13 & 0,16 & 0,04 \\
\hline
\end{tabular}

Note: * $p<0.05$; ** $p<0.01 ;{ }^{* \star \star} p<0.001$. 